\title{
Intelligent Thinking and its Relationship to Creative Thinking and the Center of Control
}

\author{
Dr. Hanan Gomaa Abdullah \\ Assistant Professor, University of Mustansiriya / College of Basic Education. Doctorhanan29@gmail.com
}

\begin{abstract}
The current research aims to identify the level of subtle thinking and its relationship to creative thinking and the control center of university students. It also attempts to show the differences in the arithmetic averages of subtle thinking, creative thinking and the control center according to gender, while finding the correlation between the three research variables. The research sample was chosen in a random, stratified, proportional method, and thus it was (300) male and female students: (187) in the College of Education and (113) in the College of Basic Education/ Al-Mustansiriya University. The study uses statistical and psychometric analysis represented by honesty and consistency. Also, the researcher prepared the measure of the control center. The results showed that university students have clever thinking, and that the students 'ability to fluency showed a higher degree than the ability of flexibility and originality. Then the ability of flexibility and finally ability of originality emerged. The results of the research show that there is no relationship between smart thinking and the control center, while there was a relationship between smart thinking and creative thinking.
\end{abstract}

Article Received: 18 October 2020, Revised: 3 November 2020, Accepted: 24 December 2020

\section{Introduction}

Skillful thinking plays a vital role in the success and progress of individuals inside and outside the educational institution because their performance in educational academic tasks, school tests, and life situations during the study and after its completion (such as relationships with others and work requirements) are the products of their thinking. According to it, the extent of their success or failure is determined. Consequently, the individual's imposition of success diminishes if teachers do not provide appropriate expertise to teach students and train them to implement the processes and thinking skills necessary for academic tasks and public tasks outside educational institutions (Jarwan, 1999).

The possession of subtle or skilled thinking must be considered for thoughtful education. It should also be dealt as directed leadership and continuous training so that one can develop the ability in this field to the fullest extent possible. This means it is a technical achievement full of ingenuity (Beyer, 1987). Creative thinking has great importance in life. It may help solving many problems and avoid dangers by anticipating danger because of the inferences and analyzes. It also contributes to solve many of the problems by using the meanings of things without the need to deal with the things themselves or treat them with realistic scientific treatment (Issawi 2007: 175). Studies have indicated the existence of significant correlational relationships between the concept of control center and a number of variables and other psychological phenomena such as performance effectiveness, susceptibility to persuasion, nervous stress and personality characteristics. For example, it has become clear that people with an internal orientation have more effective performance in solving problems. Those people show stronger resistance against the attempts of others to persuade them, and they tend to blame themselves when they go through the experience of failure. In addition, they feel more responsible compared to those with an external orientation.

\section{The study importance}

The topic of thinking has been discussed since ancient times. Also, since the Greek philosophers 
until now, there has been no consensus on how we think and how the human brain works. However, the interest in thinking in the past was a simple concern, as societies in the past were more stable (El-Demerdash \& Kamel, 1963).

The life of an individual represents a series of events and situations that require thinking. We think even if we do not want that. Therefore, we practice many forms and skills of thinking that range from simple, such as identification, recall and understanding, to complex, such as critical thinking, creative thinking, organized thinking, metacognitive thinking and high-order thinking. Perhaps, these thinking are among the elements of intelligent behavior that have called some scholars to name the person who possesses them a person who is a skilled, or expert thinker (Al-Rimawi, 2004).

Teaching student skillful thinking gives a sense of conscious control over thinking, which is reflected in the improvement of his performance and self-confidence. The subtle thinking plays a prominent and influential role for the individual in the performance of adaptations and activities without which it cannot be performed effectively. Also, thinking can be of the highest levels of cognitive organization, because it is based on perception and its use that requires the individual to have a mental activity that is more complex and difficult than the activity required by other levels (the zyoud Et al., 1999: 117).

The world has become more complex as a result of the challenges posed by information and communication technology. Also, success in facing these challenges does not depend on the amount of knowledge but rather on how knowledge is used and applied. As a result, there are tremendous and rapid developments that Arab societies are subjected to, similar to other societies that preceded it in information and communication technology. Many conferences and seminars call for learning thinking skills in everything possible in order to provide opportunities for thinking to their students. Therefore, educational goals at any stage of the school stage are not without explicit or implicit texts about the need to develop thinking. Parents and teachers often ask what causes the difference between students and children among themselves. Some accept psychological activities with great enthusiasm, while others reject them. It may take one student in a study activity for long hours, while a third can do this activity in a very short period. In addition, number of students may seek to obtain superior process levels, while others are satisfied with normal or low levels (Ecstasy, 2003: 205-207.(

Casakin, 2009 emphasized the role of the cognitive orientation in thinking for creativity. This scholar also showed the basic characteristics of the creator that are related to creativity more than related to other processes.

The control center is one of the basic concepts the social learning theory came up with in the sixties of the last century. It attempted to mix the behavioral perspective with the cognitive perspective in understanding the individual and social personality of the human being. This concept has aroused and still influences remarkable theoretical interest in various field studies of social psychology, specifically in the field Attribution (how people explain the events that pass through them and to what they attribute their source causes).

The concept of control center is attributed to Rotter who stated that when the individual realizes that the reinforcement actually follows from actions as not being totally dependent on these actions. It happens when people perceived these actions happened as the result of luck or fate because it is under the control of other unpredictable forces due to the great complexity of the forces surrounding it. Rotter also argued that when events are interpreted in this way, people believe in external control. If people realize that the events depend entirely on their own behavior, or to some extent on their personal characteristics, we call that (the belief in internal control) (Rotter, 1966.1-9-12). 
Reinforcement is reward and punishment that follow our action. It would strengthen or weaken the likelihood of doing that act again. The respect and the privileged social position of the creative person in the community is a positive reinforcement that motivates further innovation. While contempt and indifference towards it is a negative reinforcement, Fires believes that the concept of control center in its two dimensions (internal - external). This concept has in particular much discussed in research. This makes this concept the most variable of personality favored by intensive research in our modern memory for its suitability in fields such as social psychology, psychotherapy, personality and learning (Fairs, 1986, 227).

\section{Aims of the Study}

The current research aims to identify:

1. The level of skilled thinking among university students.

2. The level of creative thinking among university students.

3. The level of control center for university students.

4. Significance of differences in subtle thinking according to the gender variable.

5. The significance of the differences in creative thinking according to the gender variable.

6. The significance of the differences in the control center according to the gender variable 7. The correlation between the three research variables, and the extent of the contribution of the independent variables (creative thinking and the control center), to the total variance of the dependent variable (smart thinking) among university students

\section{The study Limits}

The current research is conducted on fourth-grade male and female students in the College of Education and Basic Education at Al-Mustansiriya University for the fourth year of the academic year 2018-2019

\section{Definitions of Terms}

First: Smart Thinking:

Costa and Kallick (2000) defined smart thinking as an evolutionary process. It aims ultimately to produce ideas and solve problems. These include tendencies, attitudes and values, and they lead to patterns of different preferences (Costa \& Kallick, 2000).

In theory, Costa and Kallick (2000) define it as an intelligent thinking.

In terms of procedures, it is the total score that the respondent obtains by answering the paragraphs of the scale of smart thinking that the researcher has adopted for this purpose.

\section{Second: Creativity Thinking:}

According to Torrance 1972, creativity thinking is the ability to produce the greatest possible intellectual fluency, automatic flexibility and originality in response to a problem or an exciting situation (Torrance, 1972, p.61).

Khairallah (1975) stated that it the individual's ability to produce a greatest amount of output as possible

The researcher adopted the theoretical definition of Torrance (1972).

The procedural definition of creative thinking could be the degree that the respondent obtains in fluency, flexibility and originality through the response to the creative thinking test.

\section{Third: Locus of control}

Rotter who stated that when the individual realizes that the reinforcement actually follows from actions as not being totally dependent on these actions. It happens when people perceived these actions happened as the result of luck or fate because it is under the control of other unpredictable forces due to the great complexity of the forces surrounding it. Rotter also argued that when events are interpreted in this way, people believe in external control. If people realize that the events depend entirely on their own behavior, or to some extent on their personal characteristics, we call that (the belief in internal control) (Rotter, 1966.1-9-12 


\section{Theoretical Background}

\section{First: Smart Thinking}

Thinking is basically centered around our a natural working mechanism in the well-being of the subconscious that works to direct us towards the completion of our work and the achievement of our goals. If it is left to work normally, it may cause negative consequences, so humans must learn how to direct the subconscious mind to obtain the desired and useful goals. Also, our inherent strength towards causing problems must be avoided to prevent failures and difficulties (Allen, 2004). Thinking of ordinary everyday life is usually stereotyped thinking that does not lead us to little growth from our experiences and knowledge. However, subtle thinking leads us to the growth of our experiences and knowledge as it leads to understanding deep in the phenomena of our lives. Thus, we could reach new conclusions and inferences with wise decisions and sound assessments, and produced new ideas for this purpose, we seek to learn smart thinking (Zaitoun 2003: 85).

Allen (2004) pointed out that smart thinking is the understanding associated with using, presenting, and communicating knowledge to others. This understanding contains countless links between small pieces of information to define the form of knowledge wanted to use. Also, the relationships and connections between ideas, events and actions become meaningful only in their context (how, where, when, and why) they relate to other ideas, events and actions (Allen, 2004).

Costa indicates that cleverness and skill are learned very early in an individual's life as it helps in managing routine activities and complex activities. Learning requires initially a set of cognitive processes starting from the process of attention, knowledge, repetition or practice. Swiftness and skill is an often unconscious pattern of behavior learned through the process of repetition. Consequently, it is established in the mind, and cleverness is a pattern of intelligent performance or behavior of the individual that leads him to productive actions (Costa and Calic, 2003: 68).

\section{Second: Creative Thinking}

Creative thinking is one of the highest levels of thinking. It is from the level of productive thinking and its definition is still ambiguous and complex because of the different trends of researchers. There are scientific views and diverse scientific interests and schools of thought to which they belong. It also has many aspects.

Creative thinking is a type of productive thinking as a mental process throughout a person's life. Several definitions of creative thinking have emerged such as Hong's report. Honig (2001) argued that creative thinking is divergent thinking. It includes breaking down old ideas, reconnecting them, expanding knowledge, generating new ideas, depending on their mental interaction. In addition, it increases the conceptual distance between the individual and experiences. MacKinnon posits that "creativity is more of a multifaceted phenomenon than a well-defined theoretical concept." Roshka (1989) believed that "creativity is the integrated unit of a group of subjective and objective factors that lead to the realization of new, original and valuable production by the individual or group". This type of thinking is important to the individual and society. This importance is because of the creative output that is achieved as a result of individuals' capacity for creativity in various aspects of life if the individual has the appropriate environment for the growth of his creative thinking (Al-Alusi, 1990).

\section{Practical Part}

\section{Study Population}

The population of the study is the students of the fourth grades of the Faculties of Education and Basic Education - Al-Mustansiriya University. Thus, the research community is (1927) male and female students divided into (730) students in the College of Education, and (1197) students in the College of Basic Education. 


\section{The Research Sample:}

The research sample was chosen in a random, stratified, proportional method. It was (300) male and female students, and (187) male and female students in the College of Education and (113) male and female students in the College of Basic Education - Al-Mustansiriya University.

The Study Tools

\section{First: Scale of Smart Thinking}

Due to the lack of a modern scale in the local environment for Al-Mustansiriya University students, the researcher built a scale according to .the scientific steps for building standards.

First: The researcher relied on the theoretical concept (Costa \& Kallick, 2000) in constructing .the scale items.

Second: The researcher analyzed two components (Costa \& Kallick, 2000) consisting of (14) elements of a skilled, skilled thinker. Through the literature (Al-Saffar, 2008) and the components mentioned by Costa and Kallick (2000) and through previous studies, the researcher designed (42) items that measures the attribute of smart thinking with (3) items for each component. Also, the researcher has adopted the self-report formula in drafting the items. The scale has developed (5) alternatives (applies to - often - applies to sometimes - applies to rarely - does not apply to me). The degrees are arranged in a descending order $(1,2,3,4,5)$ for the positive items and vice versa for negative paragraphs.

\section{Validity scale (apparent validity):}

The scale was presented to a group of 10 arbitrators specialized in education and psychology. The arbitrators approved the scale $(80 \%-100 \%)$ in terms of the validity of the items in measuring smart thinking.

\section{Statistical analysis of the scale paragraphs}

To conduct the statistical analysis of the scale items, the researcher relied on a random sample from the research community. The researcher relied on the formula for determining the size of the statistical analysis sample.

1. Distinguishing the paragraphs:
After correcting the forms that were applied to the sample of statistical analysis, the researcher analyzed the responses. Then, (27\%) forms were selected from the forms that obtained the highest scores, Also, (27\%) from the forms with the lowest scores. This percentage is the best compared to the two either end of the groups. They can be the maximum possible size and distinction (Abu Libda, 1979: 349). According to this percentage, the number of forms in each group was (80) forms in each group. The items were analyzed using the T-test for two independent samples. The results showed that scale items were of good distinction except for (2), as the calculated $\mathrm{T}$ values were greater than the tabular $\mathrm{T}$ value (1.960) at a level of significance (0.05) with a degree of freedom (158). Thus, scale items became (40).

2. The relationship of the item score with the total score of the scale:

To verify the relationship, the value of the correlation coefficient between the score of each item was calculated with the total score of the scale. Also, the Pearson correlation coefficient was used to extract the correlation coefficient. The correlation ranged between $(0.48-0.80)$, which is statistically significant, as it is greater than the tabular value of (0.098) at the level of significance (0.05) and with the degree of freedom (297.(

Stability of scale:

The scale was applied to a sample wass chosen randomly from the College of Education - Ibn AlHaytham (25 students) and the College of Basic Education (25 students).

For the purpose of checking the stability, the scale was applied to the individuals of the consistency sample. The Fakronbach method, which is one of the methods of internal homogeneity, was used. Also, the consistency coefficient is $(0.75)$ degrees. Thus, the scale is reliable and suitable for use for the final application.

\section{Second: Creative thinking test}

Creative thinking is one of the thinking types such as critical thinking and creative thinking. It is a process and a mental activity that occurs 
throughout a person's life. After the researchers reviewed the tests, measures and studies related to creative thinking, Torrance's verbal and graphic test, Jarwan (1999), Anderson and King's study (1993), Olson's study (1999), and Lipman's study (1991) were used. Thus, three creative thinking skills were identified:

1. Ideational Fluency: It refers to the production of the largest number of expressions belonging to a certain type of ideas in a specific time. It is measured by the ability to mention the largest possible number of appropriate answers and the ideas that have been generated. It represents the quantitative aspect as one score given for each idea or an appropriate answer to the requirements of the realistic environment. In addition, it excludes random ideas that are not based on logic and rationality.

2. Automatic Flexibility: It is measured by the ability to diversify ideas and appropriate answers. The more diverse and varied the ideas and belong to different fields, the higher their degree of flexibility it is. It represents the qualitative aspect of ideas and gives one degree for each discrepancy between one idea and another.

3. Originality: It is calculated by the ability to mention new, uncommon and unfamiliar answers in the group to which the individual belongs. Thus the degree of originality is high as its statistical frequency was little and unusual.

Validity of the paragraphs of the creative thinking test:

For the purpose of verifying the validity of the items (apparent validity), the creative thinking test was presented to (6) arbitrators in educational and psychological sciences to find out the validity of its items. Also, calculated Chi-square was adopted as a criterion for deleting the items, if its calculated value was less than the tabular value. It is approved, if the calculated value is equal to or greater than the tabular. It was found that Chisquare like any calculated items is greater than the tabular value of (3.84) at the level of significance (0.05) with a degree of freedom (1)..

Statistical analysis of the items of the creative thinking test:

The creative thinking test was applied for the purpose of conducting the statistical analysis of the test items on a random stratified sample of equal numbers from the two colleges. They were (298) male and female students. The honesty factor was used by calculating the correlation coefficients between the creative thinking skills represented by the skill of fluency, flexibility, originality, and overall degree represented by (creative thinking). This is by using the "Pearson correlation coefficient" to verify the matrix of internal correlation coefficients or (global truthfulness) for creative thinking. This indicates validity building.

Consistency test for creative thinking:

For the purpose of achieving the consistency of the creative thinking test, the test was applied to the consistency sample consisting of (50) male and female students. The reliability was extracted by the method of correction consistency by randomly taken the answers of (20) forms from the statistical analysis sample. They were reproduced before the correction and then the answers of the original copies were corrected. Then another researcher corrected the answers of the copies, and the Pearson correlation coefficient was calculated. The results showed that the correlation coefficient between the first correction and the other corrector was high (084(

Third: Control Center Scale:

The researcher used the control center scale (El-Helou, 1989). The scale consists in its final form of (50) items according to the fivepoint Likert style. The items are written towards internal control and another towards external control. Thus, the scale is corrected in an internal direction and given to the alternative (very agree) (5) scores, The opposite is true, if the answered is not very 
agree then a score is 1 . If the items measures external control then it substitute (very agree) with (1), but if the answer is (very disagree) then the score is ( 5) degrees, and thus the degree is graded from (1-5).

The researcher used the method of the two extremes and the relationship of the items with the total score of the scale to analyze the items statistically. The validity of the scale was extracted by the method of apparent validity, and the consistency of the scale was extracted using two methods (internal consistency 0.84 , and retesting 0.78.(
Statistical means: The following statistical methods were used to process the research data, and this was done through the Statistical Portfolio for Social Sciences (SPSS.(

1. two independent sample t-test.

2. Pearson Correlation Coefficient.

3. Alpha Cronbach Coefficient.

4. one sample t-test.

\section{Results and Discussion}

\section{Identifying the Level of Smart Thinking}

To find out the level of skillful thinking among the study sample, the T-test was used for one sample, and the results were as shown in Table (1).

Table (1) Single sample T-test results for smart thinking

\begin{tabular}{|c|c|c|c|c|c|c|}
\hline \multirow{2}{*}{$\begin{array}{c}\text { Sample } \\
\text { No. }\end{array}$} & $\begin{array}{c}\text { Arithmetic } \\
\text { mean }\end{array}$ & \multirow{2}{*}{$\begin{array}{c}\text { Standard } \\
\text { deviation }\end{array}$} & $\begin{array}{c}\text { Theoretical } \\
\text { mean }\end{array}$ & \multicolumn{2}{|c|}{ T Value } & Function \\
\cline { 4 - 7 } & & & & Calculated & Tabular & \\
\hline 300 & 125.985 & 21,87 & 120 & 4.76 & 1,960 & 0,05 \\
\hline
\end{tabular}

It appears from Table (1) that the sample have subtle thinking above the imposed mean. This gives a positive indication that university students have the ability to think intelligently and solve problems to reach a balanced state. This result is consistent with a study (Al-Saffar, 2008.(

Second: Identify the level of creative thinking.

After applying the creative thinking test to the research sample, the results were as shown in Table (2).

Table (2) Arithmetic means of creative thinking scores

\begin{tabular}{|c|c|c|c|}
\hline Ability & Number of people & Arithmetic mean & Standard Deviation \\
\hline Creative thinking & 300 & 264.22 & 80.11 \\
\hline Fluency & 150 & 145.86 & 30.84 \\
\hline Flexibility & 90 & 125.82 & 30.43 \\
\hline Originality & 60 & 90.24 & 25.14 \\
\hline
\end{tabular}

The above table shows that fluency is first followed by flexibility and then originality.

Third: The level of control center

Fourth: the significance of the differences in smart thinking according to the gender variable.

Table (3) shows the results of the third goal.

Table (3) The significance of the difference in smart thinking according to the gender variable

\begin{tabular}{|c|c|c|c|c|c|c|}
\hline Function & \multicolumn{2}{|c|}{ T value } & $\begin{array}{c}\text { Standard } \\
\text { deviation }\end{array}$ & $\begin{array}{c}\text { Arithmetic } \\
\text { mean }\end{array}$ & Number & Sample \\
\cline { 2 - 3 } & Tabular & calculated & & & \\
\hline
\end{tabular}




\begin{tabular}{|c|c|c|c|c|c|c|}
\hline 0.05 & \multirow{2}{*}{1.96} & 0.99 & 20.61 & 126.563 & 162 & Males \\
\cline { 4 - 6 } & & 21.54 & 124.537 & 138 & Females \\
\hline
\end{tabular}

It seems that there are no statistically significant differences between males and females in subtle thinking, and this indicates that the sample has the same level of subtle thinking because the political, economic, social and cultural crises have passed over everyone and helped stimulate the minds of our students.

Fifth: The significance of the differences in creative thinking according to the gender variable.

Table (4) shows the results of the fourth goal.

Table (4)T-values denote the difference in creative thinking according to gender

\begin{tabular}{|c|c|c|c|cc|c|}
\hline Ability & sex & $\begin{array}{c}\text { Arithmet } \\
\text { ic mean }\end{array}$ & $\begin{array}{c}\text { Standard } \\
\text { Deviation }\end{array}$ & \multicolumn{2}{|c|}{ T value } & Function \\
& & & & Calculated & Tabular & 0.05 \\
Creative & males & 345.92 & 94.81 & 5.86 & 1.96 & Significant \\
thinking & Females & 380.62 & 83.61 & & & \\
\hline Fluency & males & 140.11 & 36.37 & 4.35 & 1.96 & Significant \\
& Females & 151.97 & 29.98 & & & \\
\hline Flexibility & males & 121.64 & 34.60 & 4.66 & 1.96 & Significant \\
& Females & 134.28 & 31.32 & & & \\
\hline Originality & males & 85.86 & 29.37 & 399 & 1.96 & Significant \\
& Females & 95.99 & 26.13 & & & \\
\hline
\end{tabular}

The superiority of females over males in creative thinking abilities is due to the fact that females are more interested in education, and the social conditions surrounding them encourage them to spend more time studying.

Sixth: The correlation between the three research variables? The extent of the contribution of the independent variables (creative thinking and the control center), to the total variance of the dependent variable (smart thinking) among university students.

To find out the correlational relationship between the independent variables creative thinking and the control center for the dependent variable subtle thinking, the Pearson correlation coefficient was used. The results showed that there is no significant relationship between smart thinking and the control center, as the value of the correlation coefficient was (0.004), which is smaller than the value of the tabular correlation coefficient at the level of significance (0.05) and with a degree of freedom (398) and of (0.098) value. However, the results showed the existence of a significant relationship between smart thinking and creative thinking, as the values of the correlation coefficients reached (0.43), which is greater than the value of the tabular correlation coefficient at the significance level (0.05), which is $(0.098)$.

The results of the regression indicated that the calculated $\mathrm{F}$ value of the control center of $(0.007)$ value is smaller than the tabular $\mathrm{F}$ value of (3.84) at a significance level (0.05) and with a degree of freedom (1-299), as shown in Table (5).

Table (5) Regression Analysis, Intelligent Thinking and a Control Center

\begin{tabular}{|c|c|c|c|c|c|c|c|}
\hline Variab & Variance & \multirow{2}{*}{$\begin{array}{c}\text { Sum of } \\
\text { le }\end{array}$} & source & Freedom & Average of & \multicolumn{3}{|c|}{ F value } \\
\cline { 5 - 8 } & squares & squaree & squares & Calculat & Tabular & Functi \\
\hline
\end{tabular}




\begin{tabular}{|c|c|c|c|c|c|c|c|}
\hline & & & & & $\overline{\text { ed }}$ & & $\overline{\text { on }}$ \\
\hline \multirow{3}{*}{$\begin{array}{l}\text { Contro } \\
\text { I center }\end{array}$} & Decrease & 1.056 & 1 & 1.056 & \multirow{3}{*}{0.007} & \multirow{3}{*}{3.84} & \multirow{3}{*}{$\begin{array}{r}\text { No } \\
\text { signifi } \\
\text { cant }\end{array}$} \\
\hline & remaining & 63044.944 & 398 & 158.404 & & & \\
\hline & Total & 63046.000 & 399 & & & & \\
\hline
\end{tabular}

Table (5) shows the extent of the influence of the independent variable (predictor) on explaining the variance of the dependent variable (intelligent thinking) through the value of (B) for the relative contribution, the standard error of the value of
(B), the standard contribution (beta), and the t-test for this value, which is not significant. This means that the contribution of the independent variable of the dependent variable is weak as the control center contributes 0.004 of intelligent thinking.

Table (6) Contribution of the independent variable (control center) to the dependent variable (intelligent thinking)

\begin{tabular}{|c|c|c|c|c|c|c|}
\hline \multirow[b]{2}{*}{ Variable } & \multirow[b]{2}{*}{$\begin{array}{c}\text { Non-standard B } \\
\text { coefficients }\end{array}$} & \multirow[b]{2}{*}{$\begin{array}{l}\text { Standar } \\
\text { d error }\end{array}$} & \multirow{2}{*}{$\begin{array}{c}\text { The } \\
\text { standard } \\
\text { beta } \\
\text { coefficien } \\
\mathbf{t} \\
\end{array}$} & \multicolumn{2}{|c|}{ T value } & \multirow[b]{2}{*}{$\begin{array}{c}\text { Func } \\
\text { tion }\end{array}$} \\
\hline & & & & calculated & $\begin{array}{c}\text { Tabula } \\
\mathbf{r}\end{array}$ & \\
\hline $\begin{array}{c}\text { Constant } \\
\text { value }\end{array}$ & 74.201 & 4.925 & --- & 15.067 & \multirow{2}{*}{1.96} & $\begin{array}{l}\text { Signi } \\
\text { ficant }\end{array}$ \\
\hline $\begin{array}{l}\text { Control } \\
\text { center }\end{array}$ & $6.071 \mathrm{E}-03$ & 0.074 & 0.004 & 0.082 & & $\begin{array}{l}\text { Not } \\
\text { signif } \\
\text { icant }\end{array}$ \\
\hline
\end{tabular}

It appears that creative thinking contributes (47\%) of the total variance in the intelligent thinking variable.

\section{Recommendations:}

The study recommends the following:

1. Paying attention to updating school curricula and including them in programs for developing smart thinking, because smart thinking comes as a result of training and experience.

2. Preparing enrichment programs for university students that work to develop their creative thinking.

The proposals:

Based on the results of the study, the following are suggested:
1. Study the relationship of creative thinking with methods of socialization.

2. Building an indicative program for the development of creative thinking.

3. Conducting a similar study on other social strata (such as middle school students) to compare it with the current study.

4. Conducting a study to measure the correlational relations between skilled thinking and other variables not covered by the current research, such as academic statistics.

5. Preparing training programs to develop smart thinking.

\section{References}

[1] Al-Alusi, S. A. (1990). The role of education in developing innovation. 
University of Baghdad: College of Education, (Ibn Rushd).

[2] Al-Rimawi, M. O. (2004). General Psychology, . Dar Al-Masirah: Amman.

[3] Allen, M. (2004). Smart thinking skills for critical understanding and writing: Oxford University Press.

[4] Beyer, B. K. (1987). Practical strategies for the teaching of thinking: ERIC.

[5] Costa, A., \& Kallick, B. (2000). Describing 16 Habits of Mind. Retrieved August 29, 2015. In.

[6] El-Demerdash, S., \& Kamel, M. (1963). Scientific Thinking. Cairo: The AngloEgyptian Library.

[7] Honig, A. (2001). How to Promote Creative Thinking. Early Childhood Today, 15(5), 34-40.

[8] Jarwan, F. A.-R. (1999). Learning to Think, Concepts and Applications (1 ed.). Amman: Dar Al-Fikr for Printing and Publishing.

[9] Khairallah, S. (1975). Introduction to the behavioral sciences. Cairo: The World of the Book.

[10] Roshka, A. (1989). Public and Private Innovation (Vol. 14). Kweit: The World of Knowledge. 